\title{
The Saskatchewan Music Collection: Presenting the Past, Present and Future of Our Regional Music History
}

\section{By Carolyn Doi}

Recognized for its expansive geographic features, extreme climates, diverse cultures and closeknit communities, the province of Saskatchewan is an iconic part of the Canadian identity. The complex and dynamic life of the province is matched by the history of its music and a diverse arts community. To document and share this history, the University of Saskatchewan Library has created a collection focused specifically on the music of the province. The Saskatchewan Music Collection (SMC) aims to preserve local history, provide access to regional music resources and promote these items through online and on-site access.

\section{Collection History}

The SMC grew from the interests of Neil Richards, a Special Collections Assistant at the University of Saskatchewan Library, who amassed an impressive collection of rare and historical items, including memorabilia, recordings and sheet music. In 1997, Richards donated his collection to the University, where it was stored in the Special Collections Unit and named the Saskatchewan Music Collection.

In 2001, the SMC moved to the Education and Music Library, in the same building as the College of Education and the Music Department. Moving the collection allowed the Library to improve public access while supporting teaching and research. Currently, the physical collection is accessible for on-site consultation, and members of the public, students and faculty may use the listening equipment to access audio in all formats. To further promote access, a project to digitize the collection was proposed in 2010, and a first look at the online collection was launched in 2011.

Carolyn Doi is the Music \& Education Liaison Librarian at University of Saskatchewan Library. 


\section{Collection Scope}

The SMC includes any items related to Saskatchewan, including works composed, written or performed by an artist with a Saskatchewan connection, and any work on a topic related to the province. This actively growing collection includes items from the early 1900 s to the present day and represents a range of genres, including folk, country, popular, Aboriginal, religious, classical and jazz. As of March 2013, the SMC contained more than 2694 items, including sound recordings, sheet music, books, video and ephemera. Sound recordings make up the majority of the collection, and formats include CDs, LPs, 45s, 78s, cassette tapes and one eight-track tape.

Other significant historical collections of Saskatchewan's music can be found in provincial and national collections. The Saskatchewan Archives and the Western Development Museum have select historical materials, while select current popular recordings and scores can be found at the Saskatchewan Public Library. The complete works of several local composers are at provincial academic libraries, including those of Murray Adaskin and David Kaplan at the University of Saskatchewan, and Alain Perron at the University of Regina. Nationally, examples of Saskatchewan's historical sheet music and $78 \mathrm{rpm}$ records can be found at Library and Archives Canada. The Canadian Broadcasting Corporation, which features many new and emerging artists on its online digital music service $C B C$ Music, ${ }^{1}$ provides streaming access to close to 1000 Saskatchewan artists' recordings.

\section{Collection Strengths}

The prairies are host to many immigrants from around the world, and Saskatchewan has particularly significant populations from Central and Northern Europe. When the Canadian West opened to settlement after the Dominion Lands Act in 1872, many immigrants came from the Ukraine to set up farming communities. Within the SMC are a number of recordings of music to accompany special events for these communities. There are also recordings from many churches in the Ukrainian Catholic community, including the Ukrainian Catholic Women's League Chorus, Ukrainian Orthodox Youth Choir and Orchestra, S.S. Peter and Paul Ukrainian Catholic Church Choir, Choir of the Ukrainian Baptist Church and the St. George's Ukrainian Catholic Cathedral.

Aboriginal peoples form a significant percentage of Saskatchewan's population. According to the 2006 census, more than $14.88 \%$ of the population identified an Aboriginal background. This is the second largest Aboriginal population within the Canadian provinces. First Nations are the

1. Canadian Broadcasting Corporation, "CBC Music," accessed March 20, 2013, http://music.cbc.ca/. 
largest group at 64\%, while Métis people make up 34\%. ${ }^{2}$ The SMC includes many examples of traditional First Nations music, such as hand drum, round dance and pow wow songs. Notable examples include the Sweetgrass Singers, a Cree singing ensemble from the Sweetgrass First Nation near North Battleford, Saskatchewan, and the Red Bull Singers, a family-based ensemble from Little Pine Cree Nation, represented by more than 24 albums in the collection. Also present are examples of Métis fiddling, a style of music to accompany both step dancing and square dancing, including a number of recordings by well-known Métis fiddlers Hap Boyer and John Arcand. $^{3}$

While traditional Aboriginal music makes up a large part of the collection, Aboriginal artists, including Andrea Menard and Donny Parenteau, also perform contemporary or popular styles. Lindsay Knight (aka Eekwol), has received much recognition for her "compelling and experimental storytelling rhymes," ${ }^{4}$ which pay tribute to the Indigenous Cree culture using the hip hop genre. Singer-songwriter Buffy Sainte-Marie is also represented with a number of recordings, song books, magazine articles, photographs, concert programs and even a signed music contract. Born in Piapot near Craven, Saskatchewan before moving to the United States as a child, ${ }^{5}$ she has been an advocate for Aboriginal artists, helping to establish the annual Juno award for the Best Music of Aboriginal Canada.

The province is also home to a number of large community and university ensembles, including two established orchestras: the Saskatoon Symphony Orchestra, founded in 1926, and the Regina Symphony Orchestra, established in 1908. A notable item is a live recording from the debut concert of the Regina Symphony Orchestra. The university music programs have also supported a number of ensembles over the years, and the SMC includes examples from the University of Regina Jazz Band and Chamber Choir, the University of Saskatchewan Wind Band and the Greystone Singers.

\section{Collection Development}

Regional music is often difficult to locate and obtaining it can be challenging for the Library. Historical items are often few in number and hidden in private collections. These items are usually acquired through donation, or from used book and music dealers who regularly set

2. Canadian Council for Aboriginal Business, "Saskatchewan Aboriginal Population," accessed March 31, 2013, http://www.ccab.com/uploads/File/One\%20Pagers/Saskatchewan-Aboriginal-Population.pdf.

3. The Garland Encyclopedia of World Music, s.v. "The Prairies."

4. "Eekwol," CBC Music, accessed March 30, 2013, http://music.cbc.ca/\#/artists/Eekwol.

5. The Encyclopedia of Saskatchewan, s.v. "Saint-Marie, Buffy," accessed March 30, 2013, http://esask.uregina.ca/entry/sainte-marie buffy beverly 1941-.html. 
aside potential SMC items for review. eBay has also proven useful for finding rare sheet music and historical recordings.

Music by popular artists is usually available via large online vendors, but finding music by emerging or less known artists is more challenging. The Library has set up standing orders with local Aboriginal music labels, including Turtle Island Records, which distributes recordings by First Nations and Métis artists. Given the long history of First Nations and Métis people in the region, as well as the University of Saskatchewan priority planning area in Aboriginal engagement, Aboriginal music is a priority collection area serving the research and learning needs of many University and community members.

Although increasing numbers of artists are producing music within the province, acquiring this new music can be challenging. While copies of albums are often available at live shows or independent music stores, they may not be available for purchase online. The 2007 Saskatchewan Music Industry Review remarked on this trend, stating that "many Saskatchewan musicians approach distribution at an individual level, selling physical CDs at their live shows and on their websites. The market increasingly demands a digital approach to distribution." 6 The Library has established standing orders with several local record stores to systematically purchase new albums. Other sources of information include newspaper music columns, local music blogs and reports from arts organizations such as SaskMusic, which regularly announces new releases. Collecting digital-only releases has proven more challenging because licensing agreements often do not allow copying for library lending.

Despite the challenges of collecting for the SMC, the relationship building and community interaction has raised awareness of the collection within the community. Seeking acquisitions from nontraditional sources, in addition to the usual music vendors, has resulted in a diverse collection that is increasingly representative of the musical history of the province.

\section{Digitization \& Online Collection}

Digitization has also raised the visibility of the collection and of Saskatchewan's musical history. The first phase of this initiative focused on audio recordings and liner notes for historical albums, and a portion of the digitized collection is now featured at http://library.usask.ca/education/SaskMusic.php. Guiding principles help ensure that the digitization and online presentation practices are sustainable, long-lasting and searchable while

6. Joanne Crofford, Saskatchewan Music Industry Review: Final Report: The Path to Cultural Commerce. (Regina, SK, Canada: Saskatchewan Ministry of Culture, Youth and Recreation, 2007), 26. 
also remaining cost-effective and legally observant. Digitization and online implementation of the collection were undertaken collectively by the Music Librarian, Library staff members and Library IT.

By observing existing and accepted standards for content formats, metadata and sharing, the Library aims to ensure long-term survival of the collection in the digital realm. The digitized collection includes formats for preservation (FLAC and TIFF) in addition to formats to facilitate quick streaming access (MP3 and JPEG). The Dublin Core Metadata standard is used to describe and organize the online collection, while the physical collection is fully catalogued according to current standards.

To comply with intellectual property and copyright restrictions, digitized audio is presented in 30-second streaming clips for non-commercial, educational purposes only. The 30-second clip was the subject of a Canadian court case brought by the music collectives against the use of such clips in iTunes and similar services without payment. The court ruled and the court of appeal agreed that the use of such clips in that context was fair dealing for research purposes. It would seem that a similar approach would serve Library users.

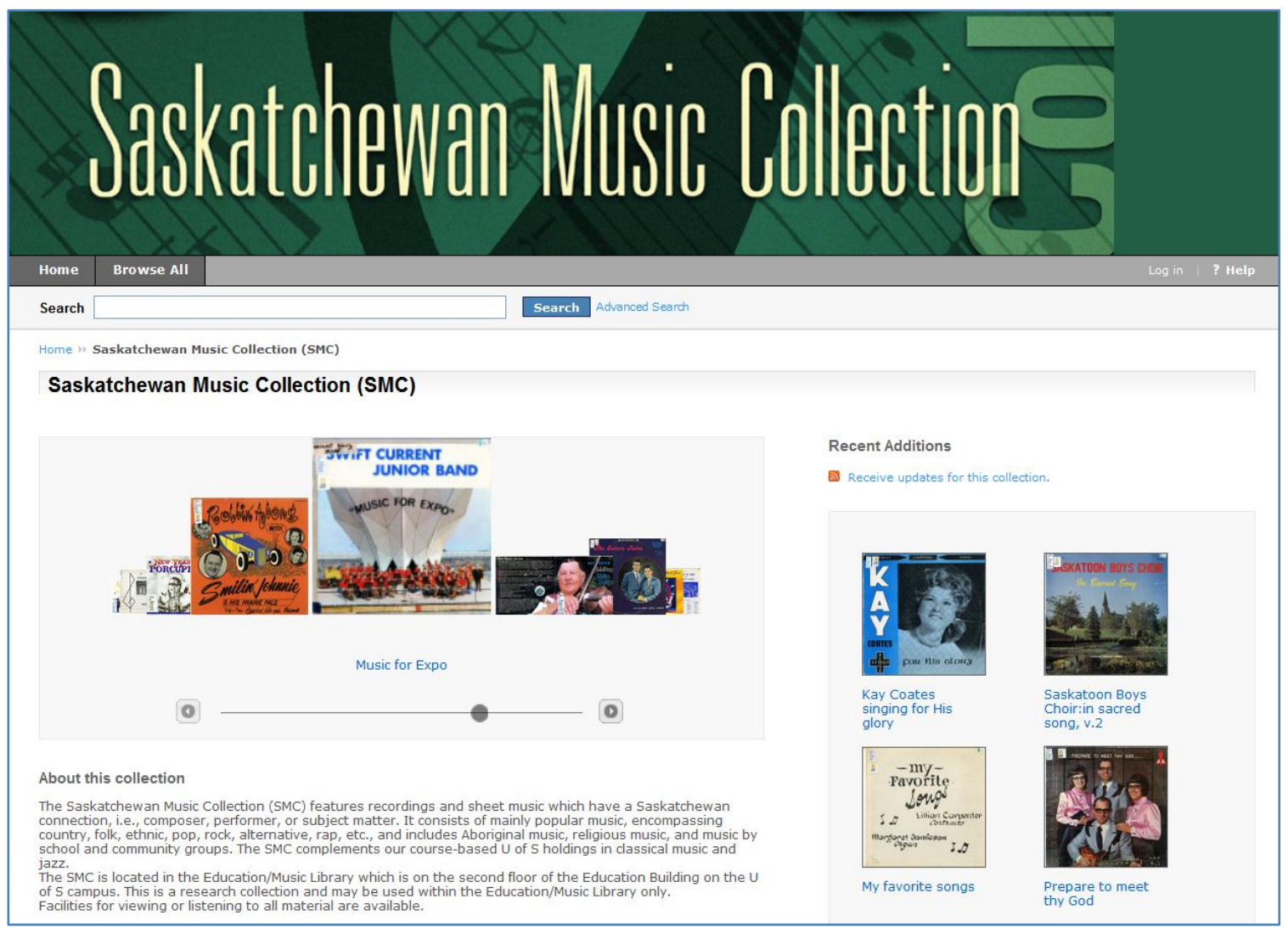


The Library used existing systems and support at the University of Saskatchewan to create a cost-effective and integrated online collection. Online access to the digitized collection is currently available through two access points: an online collection page and the OPAC. The collection page was created using OCLC's ContentDM digital collection management software, which is shared with the Library Special Collections Unit. The software includes cover display browsing in addition to basic search functionality. It also allows for mobile access and provides indexing through Google. The OPAC records link directly to the digitized files.

\section{Looking Forward}

Currently, the Saskatchewan Music Collection serves to complement the University Library community engagement strategic planning objectives and also contributes to an increasing commitment to digital curation projects. Over the upcoming year, plans are in place to incorporate the digital SMC collection with Saskatchewan History Online (SHO), ${ }^{7}$ a newly launched digital history project which features historical collections from numerous provincial organizations. SHO aims to bring together Saskatchewan's provincial history in one online location. Aligning with this new provincial resource will help the SMC reach a larger and more diverse online audience while contributing to the documentation of Saskatchewan's history.

Since the online launch of the collection in 2011, interest in the SMC has continued to grow, and research questions are increasing from around the province and country. As digitization efforts continue and more items appear online, the collection will become an ever more useful resource for study, research and investigation. Situated within a rapidly growing artistic community, there is sure to be much more to find, collect and explore in future years.

7. "Saskatchewan History Online", accessed April 5, 2013, http://saskhistoryonline.ca/. 


\section{Bibliography}

Canadian Council for Aboriginal Business. "Saskatchewan Aboriginal Population." Accessed March 31, 2013. http://www.ccab.com/uploads/File/One\%20Pagers/SaskatchewanAboriginal-Population.pdf.

CBC Music. “Eekwol.” Accessed March 31, 2013. http://music.cbc.ca/\#/artists/Eekwol.

Cottrell, Michael. "History of Saskatchewan." In The Encyclopedia of Saskatchewan. Canadian Plains Research Center, 2005. http://esask.uregina.ca/entry/history of saskatchewan.html.

Crofford, Joanne. Saskatchewan Music Industry Review Final Report: The Path to Cultural Commerce. Saskatchewan Ministry of Culture, Youth and Recreation, 2007. http://www.tpcs.gov.sk.ca/MIR-Final-Report.

Elvin, Florrie V., Kevin James, and Glen Gillis. "Saskatoon Symphony Orchestra." In The Canadian Encyclopedia. Accessed April 1, 2013.

http://www.thecanadianencyclopedia.com/articles/emc/saskatoon-symphonyorchestra.

Lewis, Merwin. "Music in Saskatchewan." CAML Newsletter 2, no. 1 (1973), 6-7.

Simonot, Colette P. "Sainte-Marie, Buffy (Beverly)." In The Encyclopedia of Saskatchewan. Accessed March 30, 2013. http://esask.uregina.ca/entry/sainte-marie buffy beverly 1941-.html.

Saskatchewan History Online. Accessed April 5, 2013. http://saskhistoryonline.ca.

"The Prairies." In The Garland Encyclopedia of World Music. New York: Garland, 2002. 